Communicable Disease Surveillance Centre gives a far better epidemiological overview of food poisoning in England and Wales than does the Office of Population Censuses and Surveys, whose statistics are mainly based on formal notifications from general practitioners.

Laboratories can, however, report only on the specimens they receive. What effects the health service reforms will have on the provision of data for epidemiological purposes remain to be seen. The relation between consultants in communicable disease control and their local laboratories needs to be formalised to enable the consultant to collate all local epidemiological information and to avoid problems of confidentiality.

Consideration should be given to a system whereby the consultants in communicable disease control receive reports on communicable diseases from all sources and are responsible not only for initiating the appropriate public health response but also for effecting the "formal notification" to the Office of Population Censuses and Surveys, thereby securing more complete and accurate national surveillance data.

The Review of Law on Infectious Disease Control has suggested that for diseases for which early public health intervention is required better methods of notification should exist. ${ }^{5}$ The Liverpool Sanitary Act 1846 required the medical officer of health to "point out the most efficacious means for checking and preventing the spread of epidemic disease." While awaiting new legislation consultants in communicable disease control can fulfil this function and, by informing clinical colleagues of the benefits of timely communication, can improve the notification of infectious diseases.

Consultant in Communicable Disease Control

Department of Public Health Medicine,

Norwich Health Authority,

Norwich NR7 0SS

\footnotetext{
Warren M, Francis H, eds. Recalling the medical officer of health. Writings of Sidney Chare. London: King Edward's Hospital Fund for London, 1987.

Committe of Inquiry into the Future Development of the Public Health Function. Public health in England. London: HMSO, 1988

Engla H. Low much do docis to

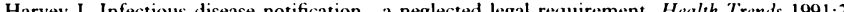
73

5 Department of Health. Reziezw of law on infectious disease control-consultation document. London: DoH, 1989.

6 Cartwright KAV, Stuart JM, Noah NI). An outbreak of meningococcal disease in Gloucestershire. Lancet 1986;ii:558-6.

7 Jones DM. Control of meningococcal disease. BMJ 1989;298:542-3.
}

\title{
Confidential medical records and epidemiological research
}

\author{
Wrongheaded European directive on the way
}

The need to use confidential medical records for answering important epidemiological questions has provoked yet another round of discussion. These cycles last about 10 years: three years to reformulate the rules, then seven years to forget them, to appoint new committees, and to embark on a new set of studies.

The iteration springs from an unresolved conflict between two views - the first that medical records are constructed only for the immediate purposes of the patient-doctor contract and should be seen by no one else, and the second, contrary view, that they have extended purposes - including communication among doctors, monitoring standards of care, managing health services, and research. The first view is associated with the absolute contractual secrecy expressed in the Hippocratic oath while the second is associated with the Geneva convention; which expresses a duty not just to the individual but to "humanity" as a whole.

The premise for such discussions is that it should be possible to devise consistent and enforceable rules that will satisfy both points of view, but the participants soon rediscover that the two viewpoints are incompatible. Health professionals may be handicapped by their scientific expectations that the world is consistent if only they can identify the rules that express its unity. The politicians and administrators are more usually baffled by the notion that health professionals should hope to find consistency in human affairs or suppose that differences can be settled rationally. The legal professionals have a vested interest in formulating rules, although they earn their salaries because the rules are never sufficient and always require interpretation. Final solutions are thus unlikely.

Evidence of the current resurgence in interest in the topic comes from Biomedical and Health Research in the European Community' and The Epidemiology Monitor', an American monthly periodical. The Monitor reports that the "European
Data Protection Commissioners" will shortly issue a directive that will "legalise epidemiology right out of existence." Another group within the European Community, the Concerted Actions Committee on Epidemiology, has published some ameliorating guidelines, but they lack operational detail and may not influence the final directive. The draft directive was formulated without their benefit, purely on legal grounds. The exercise is no more than an elaboration of principles and does not look beyond them. Its scope is restricted to the "protection of individuals," meaning nominated individuals, without any consideration of costs to others. There is no analysis of the actual and potential conflicts between the need to defend the privacy of the nominated person and the need to protect the health of others. The Monitor may therefore be justified in its anxieties.

The draft directive covers the entire field of data processing, both manual and automatic, and is comprehensively restrictive. Public health and epidemiology are not mentioned, but the new rules explicitly prohibit the processing of data "revealing ethnic or racial origin ... of data concerning health or sexual life, without express and written consent" and thus seem to bar research on many classes of sick people and on children or on other subjects incapable of giving consent, including those dead or untraceable. Even the data necessary to trace people would be denied. The proposed restrictions on personal identification would cripple many types of study. As the Monitor comments, the place of epidemiology in health research and development and the rights of the beneficiaries have been not so much misunderstood as disregarded.

The previous round of activity, 10 to 15 years ago, culminated in three reports - the report of an advisory group to the European Community, ${ }^{3}$ the report of the Lindop committee, ${ }^{4}$ and the report of the Black committee (draft code of confidentiality on personal health information), as incorporated within the reports of the Korner working party. 
The Lindop committee addressed the same broad questions covered by the draft directive, but the two other groups concentrated on medical confidentiality. Despite differences of approach they agreed that neither of the alternative fundamental viewpoints should or could be maintained at the total expense of the other. Total medical secrecy was not an absolute right of the patient or the doctor or appropriate in every circumstance, and medical records had legitimate extended uses. The two reports, however, differed in operational terms. The Black committee stated that medical records should be kept secret except when predefined and agreed conditions were valid - and it listed several pages of them. By contrast, the report of the European Community advisory group positively identified the range of purposes for which medical records could legitimately be used and then defined procedural restrictions on access.

The advisory group based its preference for formulating an operational code of practice on three main considerations. Firstly, a code declares a positive ethical duty to use medical records for the benefit of the whole population. Secondly (like the "Highway Code") it delineates a set of standards and conventions to which legislation can refer, while avoiding the impossible task of devising formal and probably harmful rules for every eventuality. Thirdly, a code with legal back up can be used to control secondary dissemination beyond the stage of the initial breach of secrecy-an essential reassurance if doctors are to be persuaded to release information for the benefit of others. The advisory group reached its conclusions after analysing hindrances to research that had already been encountered in different countries under different administrative and legal systems.

All of this is now forgotten, and there is no evidence that the present cycle in any way builds on the last one. The Monitor's anxieties should therefore be taken seriously. The directive has the marks of an incompetent and ultimately harmful operation. It exudes more than a whiff of legal pedantry, as deadly as the hazards that epidemiologists will no longer be able to investigate or public health practitioners seek to avert. It may be some time before its ill effects are felt, and we may never be permitted to know what they were; but the lives lost will be lives lost, and they are at hazard now.

Professor of Public Health and Epidemiology,

University of Birmingham Medical School,

Birmingham B15 2TT

1 Biomedical and health research in the European Community. Luxembourg: Commission of the European Communities, Directorate XII-F-6, Medical Research Division, 1991. (Newsletter No 3/91.)

\section{The Epidemiology Monitor 1991 Oct; vol 12 (No 8).}

3 Knox EG. The confidentiality of medical records: the principles and practice of protection in a researchdependent environment. Luxemburg: Commission of the European Communities, 1984. (Report of working party of Advisory Panel for Social Medicine and Epidemiology in European Economic Community.)

4 Committee on Data Protection. Report. London: HMSO, 1978. (Cmnd 7341.) (Chairman Sir Norman Lindop.

5 Steering Group on Health Services Information. The protection and maintenance of confidentiality of patient and employee data. London: HMSO, 1984.

\section{A team future for general practice}

\section{The end of the one man band}

A remarkable $70 \%$ of the 36000 general practitioners in the United Kingdom have responded to the questionnaire on the future of general practice sent out by the General Medical Services Committee. ${ }^{12}$ The GMSC undertook this survey because it was worried after general practitioners rejected the new contract introduced in 1990 that it was losing touch with the rank and file. In addition, the committee wanted general practitioners to set their own agenda rather than react to the ideas of others. General practitioners were encouraged to think the unthinkable, and that they have done so in large numbers is the vindication of a bold policy. The BMA might now be tempted to follow this strategy in its own attempt to lead rather than follow. Practical democracy can work. ${ }^{3}$

The survey suggests that doctors want to lead normal lives, which seems to conflict with patients' expectations of them. Patients want services round the clock and easier access to them, whereas general practitioners want more free time, family life, and sleep. General practitioners are, however, willing to provide more services in the time when they are working. The obvious answer to this divergence is for multidisciplinary health care teams rather than individual doctors to be the main focus of primary health care. The teams need to share a common objective and work with local schools, housing departments, factories, churches, and societies to ensure that the community is receiving the best possible health care. The population needs to feel confident that a problem taken to any member of the health care team will be passed on to the right person. Only working from shared premises where communication is good can achieve this.

A prerequisite for such a service is a review of the salary and managerial structure of the primary health care team. Innovative, high quality service should be rewarded, perhaps by allocating the whole team a budget, to be administered by the team manager and used to purchase a range of services for the population. Incorporating all the team members into one primary health care unit, with one set of managers, could resolve the currently conflicting loyalties within the team.

As general practice moves towards a more effective, proactive service society needs to consider its use of out of hours medicine. The same group of doctors that is providing an extended day time service is finding the stress of being on call too great. Deputising services may provide temporary respite but used long term they may increase out of hours requests for visits. Alternative models are possible. They include emergency primary care centres within reach of the registered population, staffed by general practitioners; mobile emergency units taking the general practitioner to the patient; or general practitioners providing primary care services in accident and emergency departments (p 735). ${ }^{\star}$ All recognise the need for the primary care health team to provide out of hours cover, but all three changes abandon the primacy of continuity of care.

Most importantly, society needs to understand that misuse of any system may destroy it. Community health councils have traditionally been the patient's watchdog; perhaps they should extend their brief to protect the health system, counselling families with high rates of use and reprimanding blatant abusers.

Also on the agenda are how we should prepare young 